twenty-four branches bearing inoculated spurs died from cankers which had girdled them by the following May.

Preliminary observation and histological studies suggest that the bacteria enter the spur via the vascular traces of the leaf scar.

East Malling Research Station,

$$
\text { J. E. Crosse }
$$

Kent. May 22.

${ }^{1}$ Wormald, H., J. Pomol., 15, 35 (1937).

Webb, P. C. R., Rep. E. Malling Res. Sta., 1949, 120 (1950).

Montgomery, H. B. S., and Moore, M. H., J. Pomol., 21, 155 (1945).

\title{
Fusaria Isolated from South Indian Soils
}

Is connexion with work on Fusarium wilt of cotton in South India, I took up in 1947 a detailed study of Fusarium floras of certain South Indian soils, particularly 'wilt-sick' black cotton soils. Wide occurrence of Fusaria in soils has been reported from a number of countries, though no such detailed survey has been undertaken in India. The present work was directed towards determining the different species of Fusarium that occur in 'wilt-sick' black cotton soils around Udamalpet (Coimbatore District, Madras State), mainly following the techniques of the traditional Fusarium investigations of Wollenweber, Reinking and others ${ }^{\mathbf{1}, 2,3}$.

In the isolation of Fusaria from soils, the 'root burial' technique ${ }^{4}$ was largely used, supplemented by the dilution-plate technique. In general the former gave a much better picture of the Fusarium flora than the latter, since Fusaria seldom appeared on dilution plates but could be easily recovered from bits of root initially buried in soils and later removed and plated out on suitable media. The following species of Fusarium were isolated from Udamalpet soils
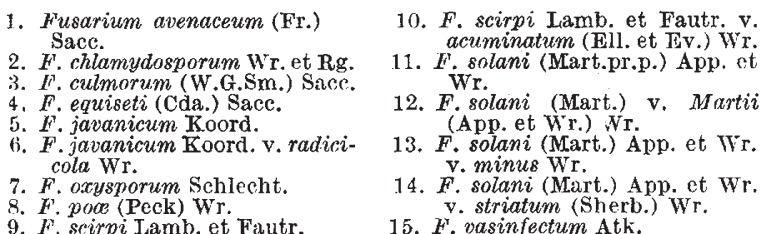

The importance, from the point of view of plant disease, of the occurrence of different species of Fusarium in 'wilt-sick' soils will become obvious when it is realized that considerable evidence has accrued in recent years indicating that some wilts and root rots of crop plants are caused by complex infections by more than one species of Fusarium. Details of the present work will be published elsewhere.

I am grateful to Prof. T. S. Sadasivan for much guidance and criticism during the course of the present work. My thanks are due to the National Institute of Sciences of India for the award of an I.C.I. Fellowship, during the tenure of which the major part of the work was carried out.

University Botany Laboratory

$$
\text { C. V. Subramanian }
$$

Madras 5.

May 12.

${ }^{1}$ Reinking, O. A., and Wollenweber, H. W., Philipp. J. Sci., 32, 103 (1927).

${ }^{2}$ Reinking, O. A., and Manns, M. M., Z. Parasitenk., 6, 23 (1933) ; Zbl. Bakt., (2 Abt.), 89, 502 (1934).

${ }^{2}$ Reinking, O. A., Zbl. Bakt., (2 Abt.), 90, 4 (1934).

- Subramanian, C. V., J. Ind. Bot. Soc., M. O. P. Iyengar Commenoration Volume, 209 ( 1946 ).

\section{Myxobacteria Mistaken for Nitrifying Bacteria}

IN connexion with the communication under this title by Miss Joyce B. Grace, published in Nature of July 21, p. 117, a careful re-reading of Winogradsky's papers on the subject ${ }^{1}$ leads me to believe that he has described two quite different species under the name of Nitrosocystis. In the first place, there is the organism isolated by Romell ${ }^{2}$ from forest soil by Winograd. sky's later technique of placing grains of soil on the surface of silica gel plates. Imsenecki repeated this work, and obtained Nitrosomonas, and a non-nitrifying myxobacterium, Sorangium symbioticum ${ }^{3}$. In the second place, there is the zooglœe-forming species, isolated by Winogradsky from Zurich soil by the enrichment culture technique, originally described in 1892 as a Nitrosomonas, and reclassified by Winogradsky in 1933 as a Nitrosocystis. This species forms the 'hard colonies' mentioned by Kingma Boltjes $^{4}$, whose work Miss Grace dismisses with the statement that there was "no evidence that the cultures were pure" ; the cultures in question, however, were single-cell isolations. As regards hard colonies, I have seen them formed by my own pure cultures of an ammonia-oxidizing bacterium, which I have every reason to believe is a Nitrosomonas ${ }^{5}$. I think that the formation of hard or soft colonies depends on the density of the silica gel in the plate, and also on whether the colony is buried or superficial ; Kingma Boltjes observed both types on his plates made from pure cultures of Nitrosomonas.

I would be inclined to think that the first "Nitrosocystis" may be a myxobacterium, but that the second is a true nitrifier, so that the genus Nitrosocystis is still valid in this sense, unless further work should show it to be identical with Nitrosomonas. I do not feel qualified to express an opinion on the genera Nitrocystis and Nitrosoglcea.

Rothamsted Experimental Station, JANE MEIKLEJOHN Harpenden, Herts. July 25 .

${ }^{1}$ Winogradsky, S., "Microbiologie du Sol" (Paris, 1949).

${ }^{2}$ Romell, L-G., Medd. Skogsförsöksanst, Stockholm, 24, 57 (1927).

${ }^{3}$ Imsenecki, A., Nature, 15\%, 877 (1946)

4 Kingma Boltjes, T. Y., Arch. Mikrobiol., 6, 79 (1935).

- Meiklejohn, J., J. Gen. Microbiol., 4, 185 (1950).

\section{Effect of cis-Cinnamic Acid and some Isomeric Compounds on the Germination of Zygotes of Chlamydomonas}

The effect of a number of organic acids as inhibitors of germination has been tested on the zygotes of the blastikos race of Chlamydomonas eugametos ${ }^{1}$. It was observed that trans-cinnamic acid inhibits germination to about 50 per cent even at a dilution of $10^{-7} \mathrm{gm}$. c.c. The experiment has now been extended to the three different allotropic modifications of cis-cinnamic acid and a few isomeric compounds. The percentage of inhibition of germination with respect to that of control is shown in the accompanying graph. The experimental method and evaluation have been described in greater detail elsewher ${ }^{2}$. The percentage germination of the control (in Volvox solution) is $85.92 \pm 0.429$ per cent $(n=1,186$ zygotes). The activity of cinnamic alde. hyde is very small, since at $10^{-5} \mathrm{gm}$./c.c. the germination remains unaffected. A similar effect is also 